\title{
Integralidade do Cuidado: prática dos profissionais de saúde do município de Cândido Mota
}

Ângela Maria Machado Major Noronha, Nelo Augusto Poletto, Roberta Oliveira Caetano

Secretaria Municipal da Saúde de Cândido Mota-SP. Serviço Social de Atenção Básica.

Rua: Antonio da Silva Vieira, 226, Centro, CEP 1988oooo, Cândido da Mota, SP, Brasil.

E-mail: gabsaude@cmotanet.com.br

O Atendimento Domiciliar desenvolvido pelos profissionais de saúde no município de Cândido Mota pretende contribuir com os hospitais e Unidades de Saúde 
humanizando o atendimento aos pacientes e suas famílias, liberando leitos para os casos que necessitam da complexidade hospitalar e reduzindo os riscos de infecção hospitalar. Nele é estabelecido um plano de cuidado terapêutico e a programação das visitas específicas ao paciente, o qual recebe visitas da equipe, procedimentos medicamentosos, curativos, equipamentos necessários e transporte. Os profissionais da rede municipal realizam ainda, quando solicitado, um relatório de contrarreferência ao hospital de origem informando as condições do paciente, após a alta hospitalar. Esse trabalho tem sido desenvolvido como modalidade à assistência integral à saúde, apresentando benefícios para todos os envolvidos e influenciando de maneira positiva na recuperação dos pacientes. 